\begin{tabular}{lllll}
\hline Motrivivência & Ano XX, & No 31, P. 132-142 & Dez./2008 \\
\hline
\end{tabular}

\title{
Esporte Escolar: aspectos pedagógicos e de formação humana
}

Rosalvo Luis Sawitzki'

\begin{abstract}
Resumo
O objetivo do estudo foi de investigar sobre a presença dos aspectos pedagógicos e de formação humana no planejamento e na prática esportiva escolar em uma escola Pública Estadual do RS. O processo metodológico consistiu de um estudo de caso, sob o aspecto qualitativo, com observação in loco do desenvolvimento das práticas esportivas e dos jogos escolares. No estudo, constatou-se discordância entre o planejamento e a prática, bem como significativa influência do sistema esportivo. Faz parte, também, do presente estudo uma proposta para as práticas esportivas escolares.

Palavras-chave: Prática esportiva; Jogos escolares; Política educacional; Formação humana; Desenvolvimento social.
\end{abstract}

\begin{abstract}
The objective of this study was to investigate the presence of the pedagogical aspects of human development in the planning and sportive practice in State Public school in RS. The methodological process consisted of a study of case in the qualitative aspect, with on-site observation of the development of sports and school games. In the study, there was disagreement between the planning and practice, and significant influence of the sportive system. Is also part of this study a proposal for the school's sportive practices.
\end{abstract}

Keywords: Sportive practice, School games, Education policy, Human development, Social development.

1 Professor Adjunto do Departamento de Esportes Individuais do Centro de Educação Física e Desportos da Universidade Federal de Santa Maria - UFSM. Av. Roraima, 1000 - Prédio 51 Camobi - Campus Universitário - KM 9. Cep: 97.105.900 Santa Maria/RS. E-mail: rosalvols@ hotmail.com 


\section{Introdução}

A prática esportiva escolar e os jogos esportivos escolares são atividades que se fazem presentes no cotidiano das escolas, envolvendo estudantes, professores, dirigentes políticos e educacionais, pais, funcionários e comunidade. A referida prática esportiva se desenvolve em dois espaços sociais: a) no sistema educacional, enquanto processo de ensino aprendizagem, e em eventos esportivos escolares; b) no sistema esportivo institucionalizado, com eventos esportivos organizados por entidades (Secretarias de Educação, Conselhos Municipais de Esporte, Federações Esportivas, Clubes Recreativos Esportivos, entre outros).

Os jogos escolares que se desenvolvem na própria escola constituem-se em eventos esportivos para os quais cada série organiza equipes representativas em apenas algumas modalidades esportivas, competindo com as outras séries em que, na maioria das vezes, participam os alunos com destaque esportivo, enquanto os demais se limitam, quando muito, à condição de torcedores. Os jogos entre escolas em atividades competitivas entre equipes representativas de cada escola, nas mais variadas modalidades esportivas coletivas e individuais (futebol, futsal, voleibol, handebol, basquetebol e atletismo), divididas em categorias para ambos os gêneros (masculino e feminino) e faixas etárias (mirim, infantil e juvenil), com idade variando entre 11 a 18 anos, geralmente abrangendo alunos a partir da quinta série.

A partir de minha experiência como professor de educação física, em escolas de educação básica na rede pública estadual do Rio Grande do Sul e, também, na Universidade na docência da formação inicial de futuros professores de Educação Física (bacharelado e licenciatura), foi possível constatar que, tanto nas aulas de educação física como nos eventos esportivos (jogos escolares), a prática esportiva envolvendo escolas e escolares se desenvolve, em geral, na perspectiva do esporte espetáculo/ rendimento, isto é, da vitória (em algumas situações a qualquer custo), da conquista, da seletividade, do troféu e da medalha, expressando a idéia de que só tem competência na prática esportiva quem vence e ganha títulos. Sob o objetivo único de "ganhar o jogo" e na ausência de princípios de formação humana e desenvolvimento social, em muitas situações, ocorrem as transgressões das regras do jogo, a agressividade física e moral, a seletividade e a exclusão, aspectos os quais se considera negativos à formação humana. Ainda é possível evidenciar que os objetivos e procedimentos da práti- 
ca esportiva escolar se confundem com os objetivos e procedimentos do sistema esportivo institucionalizado, não se distinguindo como e quando um sistema limita a prática e os princípios do outro.

Também o processo de ensino-aprendizagem da prática esportiva para crianças, pré-adolescentes e jovens está muito vinculado à lógica do mercado, na busca do resultado, esquecendo-se de respeitar as diferentes etapas de desenvolvimento pelas quais os alunos passam. Segundo Wein (2001), a grande tragédia do ensino dos esportes é que os professores conhecem bem o conteúdo (esporte), mas não conhecem os destinatários das práticas esportivas escolares, ou seja, as crianças, os pré-adolescentes e os jovens.

Observa-se que o esporte escolar encontra-se sob forte influência do sistema esportivo. Essa interferência vem ao longo dos anos determinando o modo de organização e desenvolvimento do esporte e das competições esportivas escolares, desconsiderando, muitas vezes, se existe ou não planejamento de políticas educacionais para essas atividades. Considera-se agravante que, em determinados eventos (JERGS, Olimpíadas Municipais, por exemplo), o próprio Estado estimula e aceita essa interferência, seja pela falta de objetividade e avaliação da execução de suas políticas educa- cionais, seja quanto à destinação de recursos humanos e financeiros para a realização dos eventos.

Tendo em conta o exposto e a importância dos aspectos pedagógicos e de formação humana nas práticas esportivas escolares, desenvolveu-se o presente estudo com o objetivo de analisar o planejamento e a prática do esporte escolar no contexto das políticas educacionais e do projeto político-pedagógico (propostos para o período 2002 a 2006) em uma escola da Rede Pública Estadual do Rio Grande do Sul, sob o prisma formação humana e desenvolvimento da cidadania.

Desenvolveu-se o referido estudo em razão de se acreditar que a prática esportiva escolar pode contribuir de forma significativa com o processo de formação humana e com o desenvolvimento da cidadania, enquanto componente curricular integrado a um projeto educacional. Outra razão é porque, segundo os autores Bracht (2003, 2006) e Carvalho (1987), a prática esportiva no mundo contemporâneo é um dos maiores fenômenos sociais, que ocorre através do sistema esportivo instituído na sociedade e no sistema educacional.

\section{Material e método}

A metodologia adotada consistiu em um estudo de caso, 
na perspectiva qualitativa, tendo como cerne a observação simples, in loco, do desenvolvimento das práticas esportivas e dos jogos escolares internos e jogos esportivos entre escolas, utilizando-se como parâmetros de análise (conforme Plano Integrado da Escola - PIE 2003 - 2007) os seguintes aspectos de formação humana e desenvolvimento da cidadania:

a) respeito à diversidade $\mathrm{e}$ à pluralidade social, étnica, gênero, econômica e cultural;

b) a alegria, a solidariedade, a afetividade e a cooperação;

c) justiça, diálogo, criticidade, responsabilidade e participação; da vida;

d) saúde e preservação

Os interlocutores da pesquisa foram uma Escola Pública Estadual (da 36 ${ }^{\mathrm{a}} \mathrm{CRE}$, Coordenadoria Regional de Educação de ljuí, RS), colegas professores, equipe diretiva, coordenação pedagógica, alunos e comunidade do entorno escolar.

Os dados coletados foram discutidos a partir do referencial teórico e dos documentos que tratam das políticas educacionais propostas na gestão 2002-2006, pela Secretaria Estadual da Educação SE/RS e seu Plano de Ação Pedagógico Educação de Qualidade Para Todos, o Plano de Ação do Setor Pedagógico da CRE - 2003 - 2006, o Plano
Integrado de Escola 2004 - 2007 e o Plano de Estudos do Ensino Fundamental 2004 - 2007.

\section{Resultados e Discussões}

Na análise do planejamento e da prática do esporte escolar, no contexto das políticas educacionais e do projeto político-pedagógico de uma escola da Rede Pública Estadual do Rio Grande do Sul, considerando os aspectos de formação humana e desenvolvimento da cidadania, foi possível constatar a fragmentação e a descontinuidade entre os planejamentos propostos, pelas diferentes instâncias: SE (Secretaria da Educação), CRE (Coordenadoria Regional de Educação) e escola, para as atividades esportivas (os jogos escolares e a prática escolar).

A ausência de consonância das políticas educacionais entre os órgãos gestor, o articulador e o executor (a escola) foi evidenciada por ocasião dos jogos escolares e das aulas de educação física, pois tais atividades - jogos e aulas - não se desenvolveram a partir do planejamento do projeto educacional e do projeto político pedagógico, mas, sim, sob os códigos e símbolos do sistema esportivo e do esporte de rendimento, cujos princípios são muito diferentes dos princípios pedagógicos e da escola. 
Os documentos analisados demonstraram que os dois planejamentos propostos pela escola, teoricamente, contemplaram comprometimento com aspectos de formação humana e desenvolvimento da cidadania, bem como o comprometimento com a coletividade. Os planos da escola estão constituídos de suficiente fundamentação teórica, demostrando-se claramente o que pretendia enquanto projeto educacional, de forma comprometida com a formação humana e com o desenvolvimento da cidadania. Todavia, observou-se que a prática e os referidos planejamentos, não são correspondentes.

O documento da SE/RS, em seu Plano de Ação Pedagógica, como órgão gestor das políticas educacionais, revela que a esse órgão compete definir as linhas norteadoras da concepção pedagógica para todas as escolas da rede pública estadual, com políticas educacionais centradas no desenvolvimento social de todos, tendo claro que tipo de aluno pretende formar e para qual sociedade, mediante criação de oportunidades, oferecimento de condições ou liberdade e responsabilidade de a escola definir seus próprios projetos educacionais e suas estruturas curriculares, levando em consideração as diferenças regionais, as diferentes necessidades e possibilidades de cada escola.
Entretanto, não se vislumbra essas questões nos diferentes documentos da SE/CRE.

Também não está claro e definido nos referidos documentos, o percurso a ser adotado, quem deverá participar do debate nas diferentes instâncias e como se efetivará o processo. Os documentos se constituem de planejamentos isolados, mais parecendo que cada instância cumpriu um preceito legal (ter um planejamento). A SE/ CRE constituíram dois documentos que apresentam poucas coisas em comum, dois documentos distanciados do planejamento da escola.

Quanto aos parâmetros de formação humana e desenvolvimento da cidadania, observouse que, na prática esportiva e nas aulas de educação física, em geral, os mais habilidosos apresentavam dificuldade em jogar junto com os alunos com dificuldades motoras; os meninos tinham dificuldade de jogar junto com as meninas e quando os jogos eram separados por sexo, os meninos jogavam mais tempo que as meninas; os momentos de alegria, afetividade e espontaneidade ficavam restritos às relações sociais que antecediam ao início da aula. Por ocasião das práticas esportivas, percebeu-se a falta de solidariedade, o predomínio do individualismo e manifestação do desejo de vencer a qualquer custo, a falta de coope- 
ração com aqueles que necessitam de ajuda e a dificuldade de aceitar o outro com suas limitações. Igualmente, constatou-se haver a desconsideração do outro (colega) nas relações sociais e na divisão dos tempos de jogar, pois os que tinham mais habilidades jogavam mais e os que apresentavam dificuldades e as meninas jogavam menos tempo. Ainda, as equipes eram organizados por interesses (social, econômico, afinidades....), com exclusão de alguns colegas; assim como foram observados a falta de diálogo nas tomadas de decisão e o desrespeito ao combinado no coletivo.

Conforme o observado, evidenciou-se que o planejamento pedagógico não corresponde à prática. Neste sentido, entende-se que existe a necessidade de um processo de avaliação institucional sobre a exiguidade daquilo que é planejado.

\section{Uma proposta alternativa para a prática esportiva escolar}

Considerando que a prática esportiva escolar e os jogos escolares pautados por uma política educacional, fundamentada em princípios pedagógicos, de formação humana e desenvolvimento da cidadania, apresenta-se neste estudo alguns pressupostos para a elaboração do planejamento de práticas esportivas escolares e jogos escolares no contexto do projeto político-pedagógico institucional. Nessa perspectiva, entende-se ser significativo o planejamento das praticas esportivas e dos jogos escolares com a participação da comunidade escolar, visando ao comprometimento de todos. Para essa discussão, é importante a fundamentação teórica sobre: atividade escolar; formação humana, desenvolvimento social e cidadania, contexto do projeto políticopedagógico da escola, planejados e organizados em determinados momentos pedagógicos.

Mesmo que, as práticas esportivas e os jogos escolares sejam "ainda" concebidos como de responsabilidade e de competência do componente curricular educação física, é importante avançar o debate e a reflexão sobre a possibilidade de que os jogos escolares sejam concebidos como atividade do coletivo escolar.

O planejamento participativo dos jogos escolares, com representantes de cada segmento social da comunidade escolar, deveria delimitar os seus pressupostos norteadores, as suas diretrizes, o seu embasamento teórico, os seus objetivos gerais e específicos, o processo metodológico a ser utilizado nas diferentes tapas e nas diferentes 
categorias, a regulamentação técnico-pedagógica, a adaptação de materiais e espaços físicos sempre com observância das especificidades das diferentes modalidades esportivas, de modo a ampliar a participação dos escolares. Importante, ainda, que o planejamento em apreço respeite as etapas de crescimento e desenvolvimento motor, cognitivo, afetivo e social das crianças, pré-adolescentes e jovens e esteja baseado em princípio pedagógico educacionais.

Justifica-se a importância em adaptar os materiais, espaços físicos e algumas regras, tendo em vista que existem diferenças estruturais, cognitivas, motoras e afetivas entre um adulto e uma criança na participação em atividades esportivas e jogos esportivos competitivos (GRAÇA, 1998; SÁNCHEZ, 1998 entre outros). Contrariando essas diferenças, geralmente os eventos esportivos competitivos organizados para os escolares apresentam-se na mesma lógica e estrutura dos eventos esportivos de adultos. No período de formação/iniciação esportiva escolar, alguns critérios devem ser estabelecidos, com a finalidade contribuir para o desenvolvimento integral dos jovens jogadores, sem ter pressa em especializá-los precocemente, demonstrando mais uma preocupação com uma formação esportiva plural e multilateral (KUNZ, 1994, BOMPA, 2002).
Wein (2001) afirma que as atividades esportivas e as competições formativas em cada esporte de equipe devem ser como os sapatos das crianças, ou seja, na sua perfeita medida. Se a estruturação da competição está equivocada (e hoje não existem dúvidas sobre isso), também o processo de ensino-aprendizagem dos jovens, que se orienta sempre de acordo com o que o técnico observou na competição, estará longe de ser ótimo.

Nesse contexto, há urgência em oferecer às crianças e aos adolescentes, em cada fase de sua evolução, práticas e eventos esportivos que contribuam com sua formação, adaptados ao seu nível de capacidade física, mental e social, conforme cada faixa etária.

Além de ensinar o desporto a todos e ensinar bem, a tarefa educacional exige preparar para algo mais do que a atividade específica da escola. Quem convive com a prática esportiva, pode desenvolver um acervo de habilidades diversificadas, aproveitando essas habilidades em muitas outras atividades em seu cotidiano. Afora isso, os destinatários dessas práticas poderão desenvolver a convivência em grupos, mediante participação na elaboração de regras, proposição de mudanças ou formas alternativas de prática da modalidade esportiva, de modo a contribuir de forma sig- 
nificativa para seu desenvolvimento moral e social (FREIRE, 1998). Daí a importância da utilização da prática esportiva e dos jogos esportivos no espaço escolar ser a mais ampla possível, tendo como bases e objetivos sólidos, visando a formação do indivíduo como um todo, com respeito às suas individualidades $\mathrm{e}$ capacidades.

Com base nessas observações, defende-se a realização dos jogos esportivos escolares na escola e entre escola, em duas fases: a primeira de forma interna e a outra externa. Na atividade interna, os jogos se constituiriam de atividades esportivas, de caráter lúdico/recreativa, de formação e de orientação. Nessa fase, no âmbito restrito da escola, os jogos seriam concebidos pela escola em duas etapas, ou seja, inicialmente dentro da turma de alunos e, após, entre as diferentes turmas, incluídos no projeto político pedagógico, envolvendo a todos os professores, alunos, coordenações, equipes diretivas, instituições representativas de alunos e pais em seu planejamento, organização, controle, execução e avaliação. Também os jogos internos seriam os norteadores da organização da participação da escola em processos de competições esportivas externas, envolvendo outras escolas ou redes de escola.

Considera-se de significativa importância que nas fases internas dos jogos escolares ocorra a plena participação de todos os alunos nas diferentes etapas de seu planejamento, organização, execução, controle e avaliação, sob orientação e supervisão dos professores. Ainda, sugere-se que a organização das equipes, mobilização da escola, atletas, árbitros e controladores seja construída com a participação da comunidade escolar. Nos dias de jogos outras atividades poderão fazer parte dos mesmos, como: mostra de dança, apresentações artísticas, jogos populares, jogos de tabuleiro, etc.

A fase (atividade) externa dos jogos escolares, ou seja, os realizados entre escolas deverão compreender atividades esportivas de caráter competitivo ou de caráter não competitivo (por exemplo, encontros festivos, convivência entre escolas). Estes jogos deverão ser decorrentes dos jogos escolares internos e proporcionarem atividades de formação/socialização, formação esportiva, aquisição de competências físicas, técnicas e táticas, contribuindo com a formação integral do jovem cidadão e do desportista.

Os jogos entre escolas serão organizados em fases (dependendo do número de alunos e escolas participantes no município, na região ou no Estado), em diferentes categorias (mirim, infantil, juvenil e adulto), nos naipes mas- 
culino, feminino, com diferentes atividades e modalidades esportivas (individuais e coletivas). Os jogos serão concebidos a partir de pressupostos pedagógicos formativos e organizado/estruturado pelo regulamento técnico-pedagógico, em fases municipais, regionais e estaduais, dependendo da faixa etária dos alunos e em diferentes modalidades esportivas.

Após a realização dos jogos e nas diferentes etapas, é importante desenvolver um processo de avaliação com a participação dos envolvidos, visando a verificação do cumprimento/superação das metas e objetivos propostos e, assim, provocar a reflexão sobre as ações didático-pedagógicas formativas ocorridas ou não durante o processo. Sugerem-se, como instrumentos de avaliação, a realização de seminários com a participação de todos os envolvidos e o preenchimento de formulários específicos (inclusive com a auto avaliação dos partícipes). Os parâmetros de avaliação poderão abranger os seguintes aspectos: organização do evento, atendimento/superação dos objetivos formativos e metas propostas, ações e reações pedagógicas, participação, responsabilidade, cooperação, colaboração, socialização e tolerância de cada segmento da comunidade escolar, convívio com momentos de adversidade, ação individual e coletiva na execução de tarefas e na tomada de decisão na busca de reorientar as ações didático-pedagógico.

A observância desses aspectos possibilita que as práticas esportivas e os jogos escolares no universo da escola sejam direcionados a promover o processo de formação humana, de desenvolvimento social e de cidadania dos escolares, constituindo-se em um espaço de reflexão/construção permanente. Portanto, a presença de qualquer atividade no espaço da escola deve ser analisada e refletida pelo coletivo da comunidade escolar em que estiver inserida, para que possa lhe dar sentido e significado enquanto uma atividade formativa presente no projeto educacional.

Acredita-se na prática esportiva e nos jogos esportivos escolares como mais uma atividade capaz de contribuir para o desenvolvimento individual e social dos alunos. Assim, registra-se aqui o convite a todos os colegas professores, dirigentes educacionais, dirigentes políticos, alunos, pais, funcionários e sociedade em geral, para a discussão, o planejamento, a execução e a avaliação de práticas esportivas escolares e jogos escolares sob pressupostos pedagógicos, de formação humana, de desenvolvimento social e do exercício da cidadania. 


\section{Referências}

ANDRÉ, M. E. D. A. Etnografia da prática escolar. Campinas : Papirus, 1995.

BOMPA, T. Treinamento total para jovens campeões. Campinas : Manole, 2002.

BRACHT, V, ALMEIDA, F. Q. A política de esporte escolar no Brasil: a pseudovalorização da educação física, in: Revista Brasileira de Ciências do Esporte. Campinas SP, v. 24, no 3. p 87-101. 2003. - Sociologia do esporte e educação física escolar, ; In: O fenômeno esportivo: ensaio crítico-reflexivo / Ricardo Rezer (org.). Chapecó: Argos, 2006.

BRASIL. Secretaria de Educação Fundamental; Parâmetros Curriculares Nacionais: Educação Física. Brasília: MEC/SEF, 1997. V. 7.

BRASIL. Secretaria de Educação Fundamental; Parâmetros Curriculares Nacionais: Educação Física. Brasília: MEC/SEF, 1998. BRASIL. Ministério da Educação. Lei de Diretrizes e Bases da Educação Nacional no 9394/96. Disponível em: <htpp://www. planalto.gov.br/ccivil/03/Leis/ L9394. htm > acesso em 09 de julho de 2007.

CARVALHO, A. M. Desporto Escolar: inovação pedagógica e nova escola. Lisboa : Caminho, 1987.

ESTADO DO RIO GRANDE DO SUL; Secretaria da Educação; Departamento Pedagógico; Plano de Ação Pedagógico: Educação de Qualidade Para Todos. Junho de 2003.

ESTADO DO RIO GRANDE DO SUL. Secretaria da Educação; $36^{\mathrm{a}}$ Coordenadoria Regional de Educação. Ijuí/RS. Plano de Ação.; Setor Pedagógico $36^{a}$ 2003-2006.

ESTADO DO RIO GRANDE DO SUL. Secretaria da Educação; Departamento Pedagógico: JERGS - Jogos Escolares Regulamentos: 2003; 2004; 2005; 2006.

ESTADO DO RIO GRANDE DO SUL. Secretaria da Educação; Departamento Pedagógico: Parâmetros Regionais Curriculares - PRC, 1998.

ESTADO DO RIO GRANDE DO SUL. Conselho Estadual de Educação - CEED; Lei 10.576, de 14 de novembro de 1995, alterada pela Lei 11.695 , de dezembro de 2001, sob vigência nas Escolas Públicas Estaduais do Estado do Rio Grande do Sul.

FREIRE, J. B. Pedagogia do futebol. Londrina: Midiograf, 1998.

GRAÇA, O; AMÂNDIO, J. O ensino dos jogos desportivos. 3. ed. Rainho \& Neves, Lisboa: Santa Maria da Feira, 1998. 
WEIN, H. Hacen falta de competiciones más formativas el deporte base. EFDeportes.com, Año 7, n.34, 2001. Disponível em: < http://www.efdeportes. com/ > . Acesso em: $03 \mathrm{de}$ janeiro de 2007.

. Quando el niño esta listo para disputar competiçiones organizadas? hacen falta competiciones más formativas en el deporte de base. 2001. EFDeportes.com, Año 6, n.32, 2001. Disponível em: < http:// www.efdeportes.com/ $>$. Acesso em: 03 de janeiro de 2007.

KUNZ, E. Transformação didáticopedagógica do esporte. Ijuí : UNIJUÍ, 1994.
LA INICIACIÓN DEPORTIVA Y EL DEPORTE ESCOLAR. Sánchez, Domingo Blázquez (org.) : 3. ed. Barcelona, INDE Publicaciones, 1998.

VEIGA, I. P. A. Projeto políticopedagógico: uma construção coletiva. In: VEIGA, Ilma Passos Alencastro (org.). Projeto políitico pedagógico da escola: uma construção possível. Campinas: Papirus, 1995.

Recebido: 24/fevereiro/2010. Aprovado: 21/abril/2010. 